\title{
A MODEL OF SOFT SKILL INSTRUCTION BASED ON THE LOCAL CULTURE FOR VOCATIONAL TEACHER CANDIDATES IN NORTH SUMATRA
}

\author{
Muhammad Amin \\ Faculty of Engineering, Universitas Negeri Medan \\ aminunimed@yahoo.co.id \\ Zamroni \\ Universitas Negeri Yogyakarta \\ zamronihardjowirono@yahoo.com \\ Herminarto Sofyan \\ Faculty of Engineering Universitas Negeri Yogyakarta \\ hermin@uny.ac.id
}

\begin{abstract}
This research aims to (1) find an instructional model as a guide for soft skill instruction in LPTK from the aspects of planning, implementation, and evaluation; and (2) determine the effectiveness of the use of soft skill instruction model for vocational teacher candidates. This study is a research and development with the steps adapted from Borg \& Gall. The research was conducted through five stages including, preliminary studies, developing the initial model, expert validation, limited testing, and expanded trials. The data collection used observation sheets, questionnaires, and assessment sheets. The data analysis was performed with different test by Wilcoxon Signed Ranks Test and Kruskal Wallis Test. The results of the research show that: (1) the instruction model developed are in the category of very valid based on the assessment of experts team, and the level of application suitability is at a very appropriate categories according to user ratings; and (2) the instruction model developed can enhance the ability soft skills of vocational student teachers candidate significantly ( $p=0.000)$, and improve student results were significantly $(p=0.014)$.
\end{abstract}

Keyword: instructional model, soft skills, local culture, vocational school teacher candidates 


\section{INTRODUCTION}

Education is a manifestation of human culture in which the culture always grows up and develops throughout the dynamics of the development era. The completion of education system should be continually and systematically managed not only to suit education system with the market need but also to accord with the development of science and technology in the society and to cope with the life challenge of human being. Generally the aim of education is to supply human being with the ability and autonomy to cope with the life challenge. Therefore, it is suggested that education should emerge three important aspects including intelligence, personality and skill.

In an education process, teachers play a very important role because teachers are the spearhead in an attemp to reach optimal result in education. Teacher's role in transfering knowledge is highly needed so that they must have relevant ability with the aspired transformation goal. To create competent candidates of teachers, they should be trained since they have joined LPTK (Educational institution of education personnel) so that technology education teacher and vocational teachers master educational science simultaneously. Hence, education for technology teacher candidate and vocational teacher camndidate should now show their attribute and attitude value as a new principal paradigm in teacher's education in the near future (Wibawa, 2005, p. 280). However if we traced back education in Indonesia, the last recent years it faced some weaknesses. One of them is dehumanization in education sector caused by any intervention which highlights only in cognitive and psychomotoric domain, so that affection aspect, transformation of value and moral value are neglected.

Based on the fact and recent education condition, some experts and education observers claim that indonesia is now facing multidimensional crisis which is triggered by moral decadence in which trust value fades away, value of respecting others seems to be a big non sense, even sometimes religious statement is ignored and useless. Furthermore, recently many university students often do not show of having much politeness both in campus and their environment. We also see many of them committing violation action such as doing mass brawl, sexual crime, and other crimes. It is observed that they might happen because of the education which only emphasizes on cognitif aspect as the best result by neglecting the importance of education to create multiintelligent students.

According to Azra $(2001$, p. 2) at least education should develop five categories of intelligence. They are intellectual intelligence, emotional intteligence, social intelligence, spiritual intelligence and moral intelligence. Regarding this five categories of intelligence, if they are simultaneously developed and well conducted, we can create qualified graduates who are not only smart in their hard skills but also smart in their soft skills. However, according to Sailah $(2008$, p. 9) in the curriculum of university level including in teacher candidate education, soft skill is given only around $10 \%$. It proves that the effort to enhance teacher's competence simultaneously through higher education have not reached the goal maximumly. Therefore to reach qualified teacher candidates, they should be trained not only with intellectual intelligence but also with the soft skills both related to interpersonnel and intrapersonnel management so that teachers have their own competence to develop student's skill and competence maximumly.

The problems in developing teacher candidate education get more complicated if it is seen from the learning and the guiding process. It is not only caused by the limitation of learning facilities, the unqualified lecturers but also by learning process which separate students with their social environment. This condition makes education just for formality to get legal requirement in seeking for a job on the other hand knowledge, skill, personality characters are ignored. This leads to a trouble if it becomes a habit.

Recent fact in teacher certification program nowadays shows us that some professional teachers even teach in a very conventional way without showing their professionalism as it is required. Even there is a study conducted by Manullang \& Milfayetty (2012, p. i) which states that there is no difference competence quality on their knowledge, skills, and abilities between those who have got their professional certification and those who have not got it. It shows that certification process is only abused as a legal 
process to get professioal certification. The ironic same condition also happens to the students that they do not study to get knowledge to be a good teacher in the future but only to get the diploma or bachelor degree certification.

According to Zamroni (2000, p. 1) education tends to be social stratification access. Further education system at school only to transfer what is so called by dead knowledge in which emphasizing education only at bookcentered and it is far separated from its root, source and application. The same argument comes from Samani (2010, p. 30). He claims that education does not go to this world in which education does not have any good relation to the real life aspect faced by the students. It is caused by neglection of local wisdom in the learning process. This phenomena also occurs in the education for teacher candidate so that it is time to eliminate this practice in order that LPTK can create future candidate of teacher as it is expected.

State University of Medan as one of LPTK which creates teacher candidate has set a strategy to create qualified teacher candidate in 2025. One of the way to develop it is making UNIMED (State University of Medan) as the character building university which developes learning revolution which emphasizes soft skills in the learning process. However the planning does not yet run maximumly even not yet showing the expected result.

The fact shows that the learning process in UNIMED does not run maximumly. One of indicators of it is that motivation of students to get better achievement is low, there are still many plagiarism, and there is no exact guidance for teachers to do teaching process using relevant soft skill. Besides the learning process does not yet implement studentcentered learning but still focusses on bookcentered by ignoring the real fact and social life of the student itself. Other fact shows that the good GPA is not yet comparable to the students's performance in teaching as it is required. This fact shows that there is a problem both in evaluation aspect and teachinglearnig process.

Teacher does not positionate student as a unique creature and autonomous individu and it makes education only grabs student's creative ability. Hence education should already be conducted by focussing to the real need of students. Nowadays, the condition is getting worst when the curriculum structure does not accomodate humanistic value so that personality aspect of students ignored. Based on the survey toward the student's result of study it shows that student's GPA does not reflect good performance done by students. There is imbalance competence between student's cognitive intelligent with their working performances so that it proves if cognitive intelligence is more dominant from many other ability or intelligent.

Culture and cultural value is now shiffted so that it should be maintain as an important means in character building. The shift occurs because of the social interaction and social process happened in the society with which people in the environment follow the norms and rules there. If we observe, in the society soft skill aspects such as; communication, adaptation, cooperation, and ability of problem solving are useful and applicable but ironically those soft skills are often concerned in the process of teaching and learning. Based on the fact above to create such a good teacher candidate it is essential not to separate the social-context of the students in the learning process.

Regarding the above analogy, it is necessary to integrate cultural value as soft skill attribute in the learning process for teacher candidate. Development of Soft skill with the local culture as the source in the learning process will enable students to maintain the social situation which leads to meaningful learning processand finally create very qualified and competent teacher candidate and therefore it will bring good impact for their students.

Soft skill based instruction by integrating soft skills and hard skills can be done by many ways. According to Fogarty \& Pete (2009, p. 10) there are three integration models, namely fragmented model, connected model, and nested model. Connected curriculum model is a curriculum which relate each lesson subject with the material. Whereas soft skill integration by using fragmented model will enable to integrate many subjects. Connected model soft skill is more useful for reinforcing hard skills. The last, nested model focuss on the achievement on many skills and many target. Nested model makes learning process is easlily achieved because soft skill 
can be integrated naturally without any force. This model also enable learning activity contains soft skill and the result could be measured through learning process. Research results in integrated comprehensive approach in the character building can increase the study result and target score which is being developed (Zuchdi, Prasety, \& Masruri, 2012, p. 197).

The study conducted by Beard, Schwieger, \& Surendran (2008, p. 229) informs that market industry needs the use of learning instruction which integrate soft skill aspects and its evaluation form so that the graduates have master soft skill and relevant working skills. Kapp \& Hamilton (2006, p. 2) emphasizes that soft skill instruction requires long-term organizational planning to lead the success. In soft skill instruction, every method used is very specific to achieve relevant competent so that the teacher's creativity to encourage student's learning is very important here and much influencial.

As a good teacher candidates, they should not only master the material that is going to teach but also able to transfer education value. To reach the goals it is a must for lecturer to integrate soft skills and trains four main part of the body namely; mind, intuition, body, and heart. (Elfindri et al., 2010 , p. 216). If teachers are only skillfull in transfering knowledge so that one day their role might be replaced by technology development. Therefore education for teacher candidate should get attention and integrate soft skills. Soft skill integration models can be done variously but basically it depends on the plaaning aspect before the learning process starts, learning strategy used in the learning process and evaluation method used.

\section{RESEARCH METHOD}

This study belongs to research and development research. This method is used to find out an instruction which could integrate soft skill based on local culture in the learning process for vocational teacher candidates. Research and development is used dealing with the research and the product development. Richey \& Klein (2005, p. 25) suggests three conventional ways related to this development research; (1) defining the problem, (2) literature study, and (3) research procedure.
Research and development is a process used to develop and validate education products (Borg \& Gall, 1983, p. 772). generally the process in this research is known as research cycle which includes; (1) studying the finding research which relevant to the education product which is going to be developed, (2) doing a field test in a place where the research product will be developed, (3) doing revision if there is any weaknesses found during field test. Based on the previous description, in general this research will be conducted through five stages namely preliminary studies, developing initial model, expert validation model, limited testing stage, expanded trials.

Preliminary study is done to collect some information, observe and identify problems faced in learning process and summarize problem faced by lecturer starting from making a planning, executing, and evaluating soft skill instruction. This stage involves 20 correspondences.

Developing initial model stage is conducted based on the previous preliminary study as well as based on the suggestion from the subject lecturer. In this stage researcher arrange model components in a system based on library research and theoretical framework so that the goal to integrate soft skill in the learning instruction could be reached effectively. This design includes instruction planning which integrates soft skill instruction based on local culture, learning process or activity for students, and learning evaluation. System component planned includes operational explanation from each component so that identification on the relation of each component can be observed easier.In general the planning model uses Dick \& Carrey model though some components have differences.

Expert validation model is conducted by Delphi technique through 2 chances. Expert validation involves four expert teams each of which are experts in technology and vocational education, experts in character education, experts in education technology, and experts in education evaluation. Besides becoming the expert validation team, they also give judgement and evaluation toward the developed model. The judgement aspects includes the display, system, content, and language usage. 
Limited testing stage is aimed to see the application of the model and the suitability amongst the devices used in the model. This limited testing is conducted in two limited subjects, six lecturers and twenty students to do simulation toward the product. In this stage there is also evaluation upon the model and devices by the model users.

Expanded trial is a stage to see the effectiveness of model usage. This model uses quasi experiment involving 120 students in six different subjects. The effectivity of the model is observed from the significant development of the soft skill and the student result in the learning process. The data collection method uses observation sheets, questionnaries, and assessment sheet. Data analysis is done by using t-test Wilcoxon Signed Rangks Test and Kruskal Wallis Test.

\section{RESEARCH RESULT AND DISCUSSION}

\section{Result of Preliminary Survey}

Generally integration of soft skill in the class instruction done by lecturer by considering teaching strategy (80\%). It is done because teaching activity is selected based on the goal of the study. Hence teaching activity can be used to determine the relevant soft skill that wants to be developed. Therefore this condition leads lecturer to do various strategy so that the goal of soft skill that need to be achieved could be reached maximumly and variously as well. The preliminary result of survey also shows that all respondences also try to use various instruction strategy in purposes to enhance students's soft skill and to avoid bordom for the students in the learning process.

In relation with many soft skills to develop, some respondence (55\%) integrates around 4-7 soft skills in each subject they teach. There are around 30\% respondences plan to integrate ten soft skills. However, from the research it is known that all the pplanning is not done successfully which means they only write the planning to integrate soft skills in their teaching process in the document but in fact they have never practiced it. The interview results show that generally $85 \%$ of lecturers are eager to integrate four soft skills only and in fact four skills are planned and done successfully. This results becomes a consideration to develop model and its guidance to use because in fact many of the respondences require any guidance to lead lesson which integrates soft skills attribute on it.

The result of interview and tracing toward learning process show that 35\% respondences plan and integrate soft skills in the teaching strategy and they implement it, $65 \%$ respondences do not integrate soft skills in their teaching trategy, they only focus with the teaching material without focussing on the soft skill. Their major reason ignoring the soft skills attribute because there are many obstacles such as too much planning and some of the soft skills attribute written in the lesson plan is only supposed as impact that would be reached on the other hand it has never been done during the teaching process.

Result of interview and research toward assessment of soft skill conducted by lecturers show that there are only $35 \%$ respondences conducted soft skills evaluation. Further research shows that among those who integrate the soft skills attribute are practicum lecturers who conduct their teachingprocess in laboratory. It is due to some soft skills attribute that indeed should be observed by lecturers in the laboratory and the judgement elements have already integrated with the evaluation form in the practical class. From the result of the interview, it is known that respondences who integrate soft skills, conduct it as it is planned also make evaluation. On the other hand those who do not integrate soft skills in teaching process they also do not make any evaluation to check their soft skill achievement.

To evaluate student's soft skills during the teaching process, there are $40 \%$ respondences assumed that evaluation is not needed thus developing assessment instrument is not done. However there are $60 \%$ respondences stated that it is needed to develop soft skills assessment instrument. According to them assessment is done by integrating the soft skills assessment with the standard competence evaluation in each lesson subject.

\section{Result of Preliminary Product Development}

Phylosophy and Concept of Supporting Theory

Education is a process which emphasizes on the individual, society, and culture development. Thus education should be able to refresh new method as well as policy which 
always relate to knowledge, new technology and social changing. Based on pragmatism theory, education is a process of reorganization and reconstruction of individual experiences.

Experience construction is not only individual-characterized construction but also social-characterized construction. Dewey acknowledges that thought as a product of interaction between organism and environment. Whereas knowledge in his perspective has a practical board in interaction control (Gribov, 2001, p. 373). Therefore it shows that education should involve society because education acts as a constructive institution to develop society. The real impact of education for society in the form of development is not only observed from student's and youth progress but also from the society progress. One of the way to involve the society progress in the process of education is by identifying any expectation of society toward the value they want to reach from education especially in the form of soft skills.

Dewey's theory of pragmatism more emphasizes individual interaction toward their environment. The goal of study is taken from a society where the students live in. This is because education runs in this life. The goal of study is not outside the life but even inside the life itself. To compose an education program pragmatism theory declares three criterias to be considered, (1) goal of study should be referred to the ongoing situation in the real life, (2) the goal of study should be flexible, (3) the goal of study should provide individuals with special needs. (Miller, 1985, p. 67) in Dewey perspective tthe goal of study is temporarily characteristic which means if a goal is reached, so the result of the goal becomes instruments to reach the next goal.

Pragmatism and prenialism concept and ideas are also relevant to the perspective of many of contemporary psychologists who explain constructivism theory from many types to elaborate how people learn. The idea in this theory is in the structure formulation and improvement continuously toward a thought that might hamper knowledge. This structure is known as scheme. Whenever new understanding, experience, action, and information assimilate and stored so scheme might be changing. Learning process both in cognitive domain, affection domain and psychomotoric domain is known to involve individual transformation process (Fry, Ketteridge, \& Marshall, 2013, p. 10). Therefore, people are actively develop their knowledge to develop the exixting scheme.

The most welknown educators, Piaget and Bruneradalah have almost the same perspective toward constructivism theory. For instance, Bruner's idea named free discovery learning claims that learning process will run well if it is given a chance to find out concept, theory, regulation or knowledge addition through real example in the real life. Meanwhile, Ausubel creates theory of meaningful learning in which learning process will be much easier if it is related to the background knowledge of the learners.

Constructivism states that we learn by adjusting the former understanding and knowledge with the later ones and also we adjust the new knowledge to our own understanding. Therefore, educators should realize that learners are not blank sheets but they have already got background knowledge which need to be developedso that there is much better changing and understanding toward one concept. On the other word it means that the learning principles in constructivism are (1) knowledge and understanding are constructed by each individuals, (2) knowledge, understanding can not be transfered from teacher to learner (no knowledge transmission), (3) learners should construct their understanding continuously till they reach concept changing themselves, (4) educator only helps in providing facilities and provide conducive situation to make learning process runs well.

It is quite often that learning process is emphasized only on how to add new knowledge but there is one more important thing that is to know how to create such a transformation to emerge additional of knowledge that they have already had. Additional of knowledge which means fact accumulation sometimes can occur without substantial transformation but in a higher level of learing process which involves creativity and higher understanding, it can only occur when the existing scheme is changed to get better understanding.

One of education experts who is relevant to constructivism theory is Lev Vygotsky that creates theory of Zone Proximal Development (ZPD) which states that the ability of problem solving need guidance from 
adult or need cooperation with colleague (Kozulin, 2007, p. 18). This aims to eliminate the gap between the learner's background knowledge with the real condition. Beside theory ZPD, there is also theory of Scaffolding which strengthens the information that guidance should be given in the initial learning process and then let the learners to take their responsibilities in the next learning stages. This concept can be the basic in arranging scenario of soft skills instruction in class. The basic concept of ZPD is that psy-chology development and learning process are sociallyconstructed and to understand the concept we should analyze the surrounding people and social interrelationship.

Further, it is important to know that learning process for higher students is quite relevant with the learning theory of adult (from the age perspective, learning method, or ethnic, economic, and education background) (Fry et al., 2013, p. 16). Therefore the adult principles of learning should be considered in the higher student's learning process such as (1) when someone gets more mature, he/she will be easier controlling themselves, (2) adult people have collected many experiences as study sources, (3) adult will be ready to study when they need to know of something, (4) adult tend not to be focussed to subject of thing but they much focuss on problems, (5) for adult, the strongest motivator is internal.

Besides constructivism theory, learning instruction developed also get support from behaviorism theory which emphasize on environment role, the importance of exercises toward the changing of behaviour, and emphasize mechanism result of learners. Thorndike perspective which leads to readiness and exercise also he states that learning curriculum should be integrated with learning material needs to be considered in learning instruction (Schunk, 2012, p. 108). Soft skills instruction that is integrated with the lesson subject is very relevant toward this theory, so that when it is implemented, we can consider Thorndike's principles (Schunk, 2012, p. 106) such as, (1) formulate habit, do not ever hope that habit is well formed without you make it, (2) be aware not to make habit that might be changed in the future, (3) do not make two or more habit if you think one is enough, (4) if everything runs as it is expected, formulate habit by which it will be used later.
Generally behaviourism admitted that to make complex behaviour it is needed formulation step by step leading to expected development. Therefore exercises are needed to strengthen responses which leads to discriminative stimulus. Complex skills can be developed by doing progressive approxi-mation toward expected behaviour. Hence, learning process should have clear objective, measurable, step by step, and strengthening.

\section{Components of Model}

The fundamental component from soft skills instruction contains of planning, implementing, and evaluating. As a learning instruction model, so during its implementation it is supported by some components of soft skill attribute, learning strategy, assessment, curriculum, and human resources.

Instruction planning is one of the fundamental component from soft skills instruction model based on local culture. planning agenda is an important part which determines the success of soft skill instruction model integratively. To do planning, it is needed to see the curriculum, the learning sources, and the guidance of soft skills instruction model. All the steps in planning programs is shown in Picture 1.

Identification cahracteristic of lesson subject is done by analyzing the available curriculum especially syllabis component used so far. Information sources used to find out lesson subject is the applied curriculum. The characteristics of the lesson subject that should be known is the goal of study observed from the indicator (expected output and outcome) so that the objective to reach and the process to do is getting clear. Identification also done by teaching experience in the previous study, so that the lesson subject could be clearly observed.

The selection of soft skills attribute should be fixed with the objective of the study seen from the characteristic of the lesson subject and the expected competence for the students. The technique of selection is finding out information from learners, lecturers so that the soft skills attribute is under their responsibilities. The chosen attributes are soft skills attribute which based on local culture as the research result from the previous research. The previous research shows that there are 16 soft skills attributes that are relevant to be 
given toward teacher candidates namely, (1) religious, (2) discipline, (3) visioner, (4) cooperative (5) leadership, (6) adaptative and flexible, (7) tolerant/ friendly, (8) oral communicative, (9) written communicative, (10) solving problem, (11) confidence, (12) care/ pay attention, (13) service, (14) Honest/ consistent, (15) responsible, (16) exemplary. The result of the research above is the verivication result from twelve vocational schools spread in north sumatra region. The result which based on local culture should be able to be used as supporting model in learning instruction suited to the applied curriculum.

Planning the instruction program supports the achievement of the goal of study. The implementation of the activity should consider the characteristics of the lesson subject and sould be supported by proper theory. For example, to reach soft skill of cooperative and colaborative, lecturer can use collaborative study by asking learners to do small group discussion method, presentation in small group, and develop planning agenda.

Evaluation which is going to be conducted is of course evaluation which is best suit to the achieved competence as well as to the soft skills which is integrated to the lesson subject. Authentic assessment is very important because by using this assessment the result will be clearly observed.

Soft skill instruction based on local culture is a part of instructional model from the planning program. The learning instruction stages includes the learning contract, group discussion making, and implementation of learning instructional process. The process of learning includes orientation, observation, question and answer, exploration, experiment, sosialisation, and reflexion. The stage of soft skills instructional model is shown in Figure 2.

Soft skill instructional evaluation model based on local culture is a part of model which can not be separated from the planning and implementation instructional model. It shows the result of planning and implementation process of learning. Some stages that are conducted in this step include (a) providing evaluation instrument, (b) doing routinely evaluation and observation, (c) analyzing the result of daily routine assessment, (d) reflecting the result of daily assessment, (e) Doing formative test/ evaluation, (f) reflexting formative test result, (g) planning follow up program. The result of overal evaluation is in a form of document and feedback note for the next term.

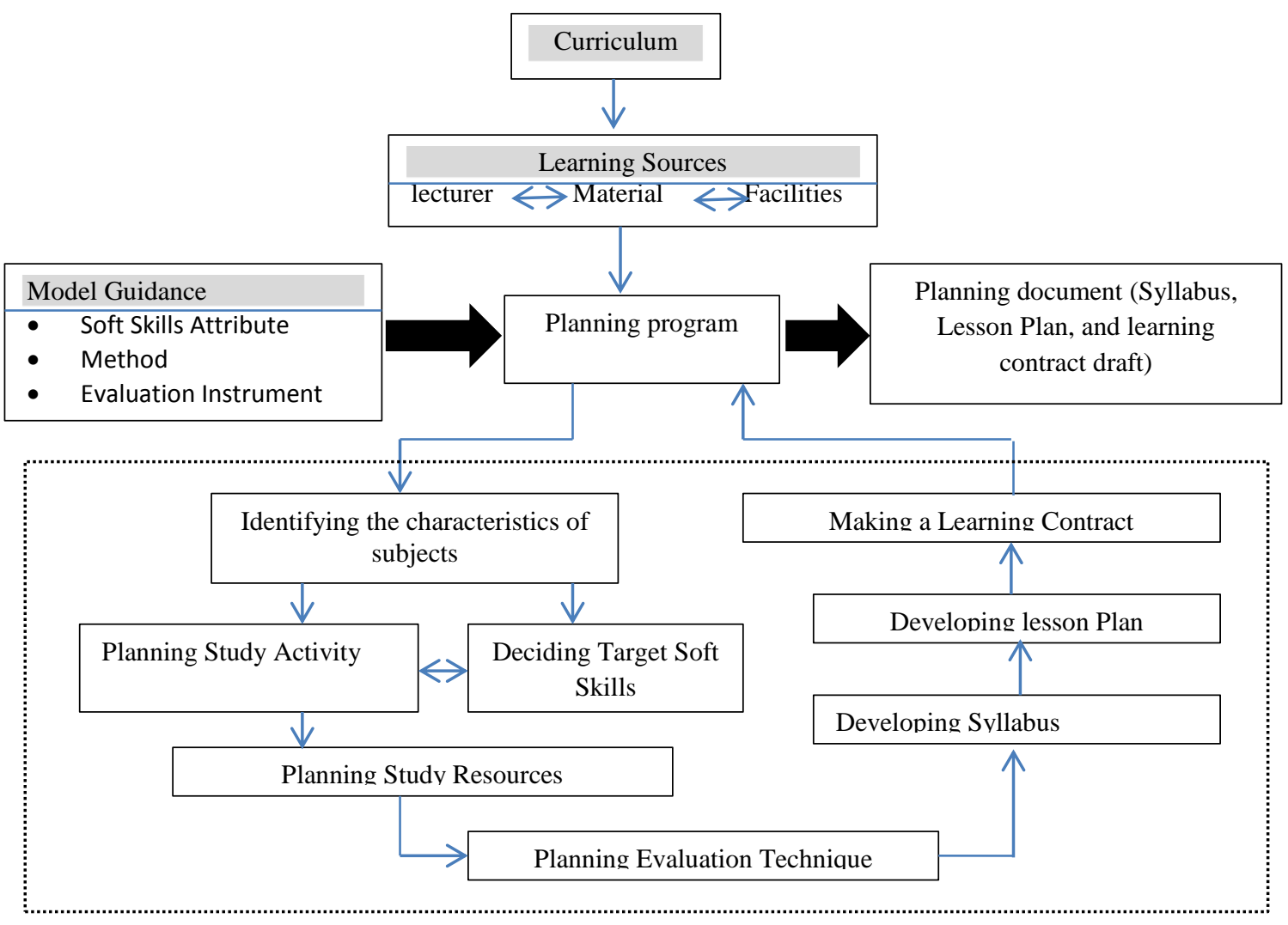

Figure 1. Soft Skills Instruction Planning Model 


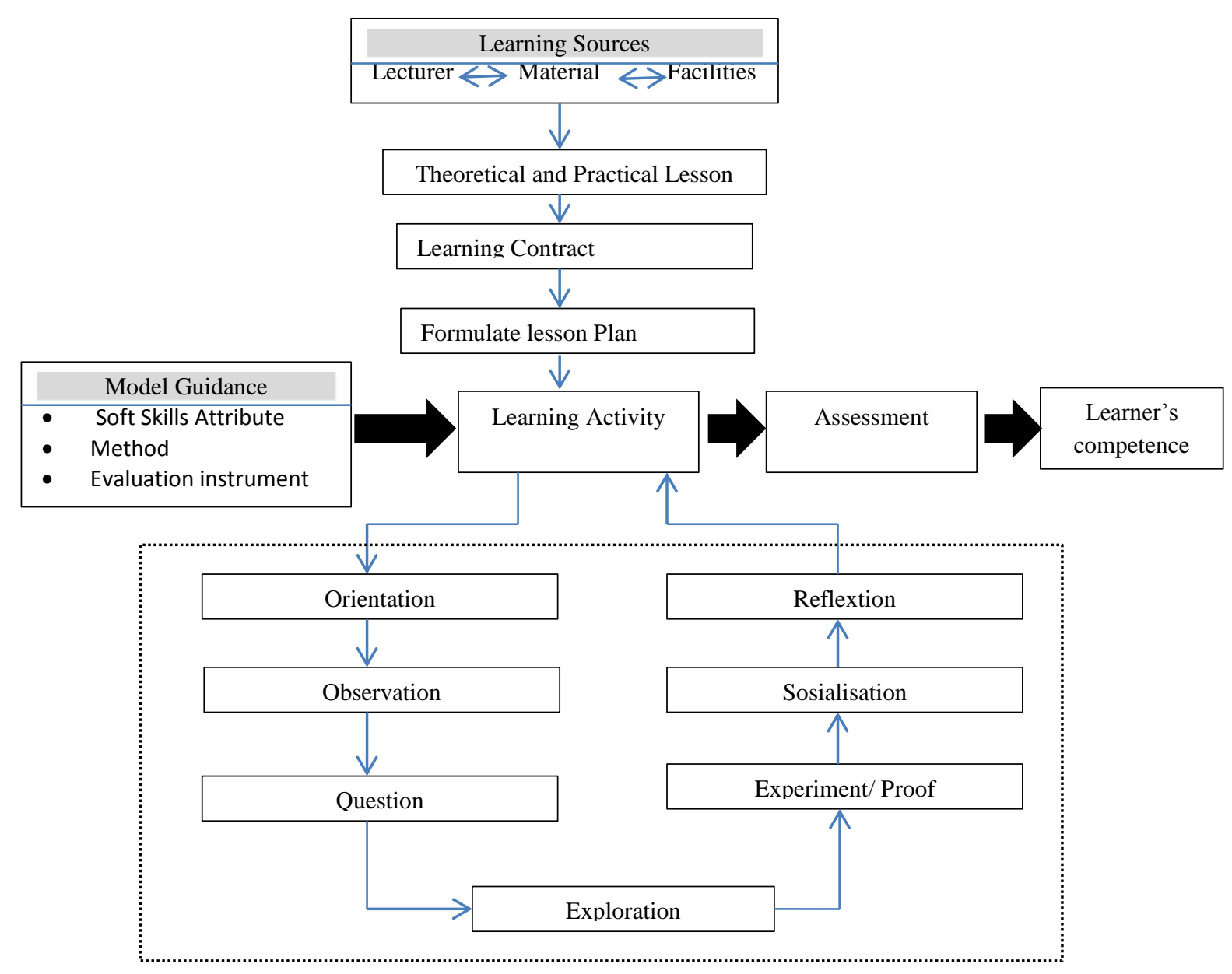

Figure 2. Soft Skills Instructional Implementation Model

\section{Validation}

Initial validation design model involves four expert teams as validators. Validation is done as it is planned that is two rounds. In the first round, the initial concept model is sent to the validator to be checked and analyzed then they gives some initial suggestion based on the concept made.

There were some suggestions from validators regarding the initial design model such as (1) it needs to explain the phylosophy and theory that support the design so that the model can be used as a whole until its implementation, (2) it needs to revise the mistake about the concept, and the use of language, verbal use of language, visual communication, consistency, and appreciation. (3) It needs to consider the limitation of soft skills integrated to make the observation gets valid and reliable toward each soft skill. It should be done since there are two many soft skills (16 skills), so that it needs only 3-4 soft skills or indicators.
(4) arrangement evaluation instruments which should consider the learning process at class so that the evaluation instrument could really measure what to measure.

The evaluation result toward initial concept model is shown by table 1 . Based on the average result of evaluation in the first round, it is found that the average score for the evaluation is 2,83 and it belogs to valid category. Recommendation given by validators is that he model can be used through many improvement. It shows that the initial model made still needs some improvements.

Table 1. Evaluation Result Toward Initial Model Design

\begin{tabular}{cccc}
\hline No & $\begin{array}{c}\text { Evaluation } \\
\text { round }\end{array}$ & $\begin{array}{c}\text { Average } \\
\text { score of } \\
\text { validator }\end{array}$ & Note \\
\hline 1 & First round & 2.83 & Valid \\
2 & Second round & 3.67 & Very Valid \\
\hline
\end{tabular}


Suggestion and recommendation given in the frst round of validaton is then followed and amended as it is suggested. The result of improvement after the first round of validation is then sent to the validator for the second round validation. the suggestions and recommendations were also needed in the second round. Based on the validation in the second round, it shows that average score is 3.67 in the catogory of very valid. Therefore this is go hand in hand with the validators recommendation that the model could already be used for limited testing.

\section{The Result of Limited Testing}

In the limited testing activity, there is also evaluation from lecturers toward the use of limited testing (Table 2). In general it is shown that learning instruction model was used well and suited to the user's expectation. However, based on the interview result there were some technical ractification such as the use of students identification number and perfection in the evaluation instrument in class discussion.

Table 2. Evaluation Result Toward Model Implementation by Lecturer

\begin{tabular}{clcc}
\hline No & Evaluation round & Average & Note \\
\hline 1 & Planning & 3.70 & Very proper \\
2 & Implementation & 3.70 & Very proper \\
3 & Evaluation & 3.64 & Very proper \\
\hline
\end{tabular}

Based on validation and evaluation result from the model users it is known that the designed model has been fit and proper to use.

\section{Result of Expanded Test}

Based on the data in pIcture 3 it is clear that the average of student's soft skills ability increased every meeting. It reaches about $9.28 \%$ every meeting. It the result is observed every formative cycle, the increasing average of soft skills from cycle two to the third cycle reaches $30.51 \% 9$ (from the average of 1.51 to 2.17), whereas from the third to the fourth cycle it reaches $26,47 \%$ (from average of 2.17 to 2.95). The increasing score of soft skills ability also changed significantly by using Kruskall-Wallis test with Chi Square. Using SPSS Program, it is seen that chi square reaches $71.42 \%$ and chi square in table as much as 19.7. Therefore average score of student's soft skill in each meeting changed significantly with $p=0.000$.

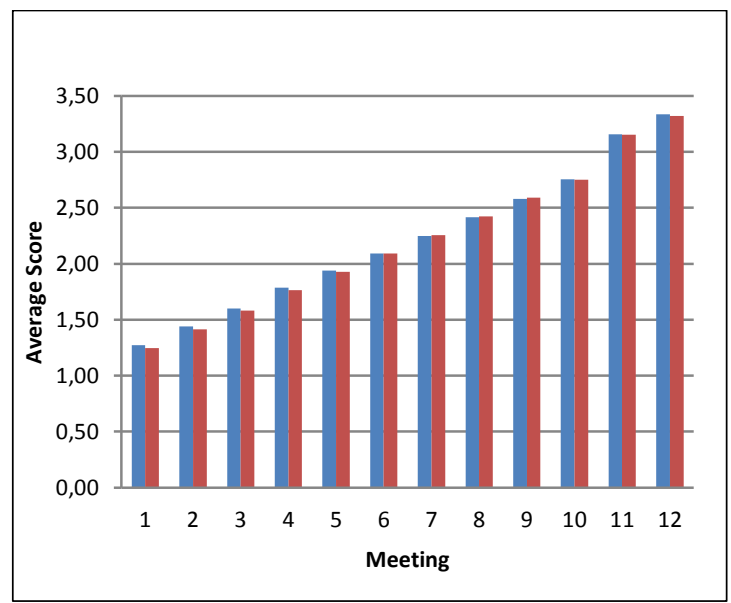

Figure 3. Student's Soft Skills Average Score

The study result of the students before and after using the soft skill instruction model is shown in table 3 . The test shows that all lesson subjects that becomes research subject give different result compared when they did not use the developed model. It is also known that the result of their study after they used the developed model increased significantly $(p=0.014)$. Hence it clearly shows that the use of soft skill instruction model can be effectively increased the result of learning process.

Table 3. Summary of The Student's Result of Study Before and After Using The Developed model

\begin{tabular}{cccc}
\hline No & Subject & $\begin{array}{c}\text { Result } \\
\text { before using } \\
\text { the model }\end{array}$ & $\begin{array}{c}\text { Result after } \\
\text { using the } \\
\text { model }\end{array}$ \\
\hline 1 & A1 & 81.79 & 89.61 \\
2 & A2 & 80.22 & 84.06 \\
3 & A3 & 81.19 & 84.26 \\
4 & B1 & 74.14 & 84.43 \\
5 & B2 & 77.08 & 81.83 \\
6 & B3 & 81.81 & 89.81 \\
\hline
\end{tabular}

\section{CONCLUSION}

The development of Soft skill instructional model based on local culture integratively in the planning program is a part of 
model which determines the success of the implementation of soft skill instructional model. The stages in planning program in this model are (a) identifying characteristics of lesson study, (b) planning learning activity, (c) deciding soft skills target, (d) planning relevant study resources, (e) designing evaluation technique, (f) develop syllabus, (g) develop lesson plan, (h) making a learning contract. The result of planning activity is in the form of planning document which consists of teaching syllabus, lesson plan, and draft of learning contract. The result of limited test shows that this planning program runs well and considered to be very proper. Therefore each stages in planning program can be used to enhance teacher candidate's soft skill.

The development of soft skill instructional model based on local culture in the aspect of implementation is also part of the result of planning program. The stages in this phase includes decision making on learning contract, formulate group discussion, conducting teaching and learning activity. The implementation of the model uses some stages include orientation, observation, questions and answer, exploration, experiment/ proving, socialization, and reflexion. The implementation stages as stated is really suited to the judgment or evaluation of the model users. Therefore the model is good to use in the learning instruction for the vocational school teacher candidates.

The development of soft skill instructional model based on local culture in the aspect of evaluation is part of model which can not be separated from the planning program and implementation program. It shows the result of planning and implementation process of learning. Some stages that are conducted in this step include (a) providing evaluation instrument, (b) doing routinely evaluation and observation, (c) analyzing the result of daily routine assessment, (d) reflexting the result of daily assessment, (e) Doing formative test/ evaluation, (f) reflexting formative test result, (g) planning follow up program. The result of overal evaluation is in a form of document and feedback note for the next term opportunity. The result of evaluation toward the program of evaluation test by users is in proper category. Therefore this model is relevant to be used to increase student's soft skills and their study result.
The use of soft skills-integrated instructional model is effectively enhance student's soft skills and student's study result. Data analysis result using chi-square toward observation on student's soft skill result shows that there is significant improvement in each lesson subject $(p=0.000)$. Based on result analysis using Wilcoxon Signed Rangks Test also shows significant improvement in the learning process before and after using the developed model $(p=0.014)$. This shows that the average of student's result in learning gets improved compared when they haven't used the model.

\section{Suggestion}

To create competent vocational teacher candidates in relation to the use of developed model, so one of the steps that needs for us to do is giving a training about the soft skill instruction toward lectureres who teach LPTK which trains vocational teacher candidates. It is done because lecturer is the key point to be successful in implementing the model.

Reagarding the development of soft skill instructional model could reach the expected goal, so an attempt to enrich soft skill attributes variously in all lesson subject is needed in order to create competent vocational teacher candidate. One of the ways to do that is doing research and study toward characteristic of some lesson subjects which could support teacher candidate's competence and its relevance with other soft skill attributes.

To increase the quality of study process for vocational teacher candidate, it is needed that the school principles or policy makers who teach the teacher candidate follow the result of this study. It is to give a chance that the policy could be implemented totally and simulatneously because the student's ability could not be measured only on some subject lesson using this soft skill instructional model but also to all subject lesson. Total implementeation of this model ensure the teacher's ability to do their best performances in the near future when they become real teacher.

\section{REFERENCES}

Azra, A. (2001). Pendidikan akhlak dan budi pekerti: "bembangun kembali anak bangsa." Mimbar Pendidikan, XX(1). 
Beard, D., Schwieger, D., \& Surendran, K. (2008). Integrating soft skills assessment through university, college, and programmatic efforts at an AACSB accredited institution. Journal of Information Systems Education, 19(2). Retrieved from http://jise.org/Volume19/192/Pdf/V19N2P229-abs.pdf

Borg, W. R., \& Gall, M. D. (1983). Educational research: An introduction (4th ed.). New York: Longman Publishing.

Elfindri, R. J., Wello, M. B., Tobing, P., Yanti, F., Eriyani, Z. E., \& Indra, R. (2010). Softskills untuk Pendidik. Padang: Praninta Offset.

Fogarty, R. J., \& Pete, B. M. (2009). How to integrate the curricula (3rd ed.). California: Corwin A SAGE Conpany.

Fry, H., Ketteridge, S., \& Marshall, S. (2013). Hand book teaching and learning strategi peningkatan mutu pendidikan di perguruan tinggi (Terjemahan Ahmad Asnawi). Panam Tampan Pekan Baru Riau: Zanafa Publishing.

Gribov, S. (2001). John Dewey's pragmatism and moraledu cation. In S. Rice (Ed.), Philosophy of Education 2001. Retrieved from http://ojs.ed.uiuc.edu/index.php/pes/artic le/view/1921/632

Kapp, M. K., \& Hamilton, B. (2006). White paper: designing instruction to teach principles (soft skill). Retrieved August 2, 2012, from http://www.karlkapp.com/materials/teac hing principles.pdf

Kozulin, A. (2007). Psychological tools and mediated learning. In A. Kozulin, B. Gindis, V. S. Ageyev, \& S. M. Miller
(Eds.), Vygotsky's educational theory in cultural context (pp. 15-38). New York: Cambridge University Press.

Manullang, B., \& Milfayetty. (2012). Model efektifitas kompetensi guru, knowledge, skill, and abilities. Medan.

Miller, M. D. (1985). Principles and A Philosophy for Vocational Education. Columbus, Ohio: The Ohio State University.

Richey, R. C., \& Klein, J. D. (2005). Developmental research methods: Creating knowledge from instructional design and development practice. Journal of Computing in Higher Education, 16(2), 23-38. https://doi.org/10.1007/BF02961473

Sailah, I. (2008). Pengembangan soft skills di perguruan tinggi. Jakarta: Direktorat Jendeal Pendidikan Tinggi.

Samani, M. (2010). Menggagas pendidikan bermakna: integrasi life skill-KBK-CTLMBS. Surabaya: SIC.

Schunk, D. H. (2012). Learning theories an educational perspektif (teori teori pembelajaran: perspektif pendidikan) (terjemahan Eva Hamdiah dan Rahmat Fajar). Yogyakarta: Pustaka Pelajar.

Wibawa, B. (2005). Pendidikan teknologi dan kejuruan: manajemen dan implementasinya di era otonomi. Surabaya: Kertajaya Duta Media.

Zamroni. (2000). Paradigma pendidikan masa depan. Yogyakarta: Bigraf Publishing.

Zuchdi, D., Prasety, Z. K., \& Masruri, M. S. (2012). Model pendidikan karakter: terintegrasi dalam pembelajaran dan pengembangan kultur sekolah. Yogyakarta: UNY Press. 